\title{
ПРИМЕНЕНИЕ РЕНТГЕНОДИФРАКТОМЕТРИЧЕСКОГО МЕТОДА ПРИ ИЗУЧЕНИИ ВЕЩЕСТВЕННОГО СОСТАВА САПРОПЕЛЕЙ
}

Сапропели представляют собой сложные современные отложения, в составе которых наряду с органическим веществом (OB) присутствуют терригенные и карбонатные компоненты аллохтонното или автохтонного характера. Состав и происхождение сапропелей обычно определяют различными химическими методами (валовой анализ, определение зольности, элементного и группового составов и др.). Авторами сделана попытка изучить вещественный состав сапропелей методом рентгеновской дифрактометрии, уделив особое внимание определению карбонатности и 'количества ОВ, а также влиянию ОВ и минеральной части на качество и количество золы образца. Соответствующие определения проводились в кабинете минералогии Тартуского государственного университета на дифрактометрах ДРОН-05 и УРС-50 ИМ с применением блока детектирования сцинтилляционного типа БДС-6 и БДС-8. Для проведения анализа иопользовано отфильтрованное $\mathrm{Fe}_{\text {K }}$-излучение. Чтобы получить максимальную информацию, дифрактограммы снимали в пределах углов $1-45^{\circ}$ при следующем режиме дифрактометров: напряжение на рентгеновской трубке 27 кВ и сила

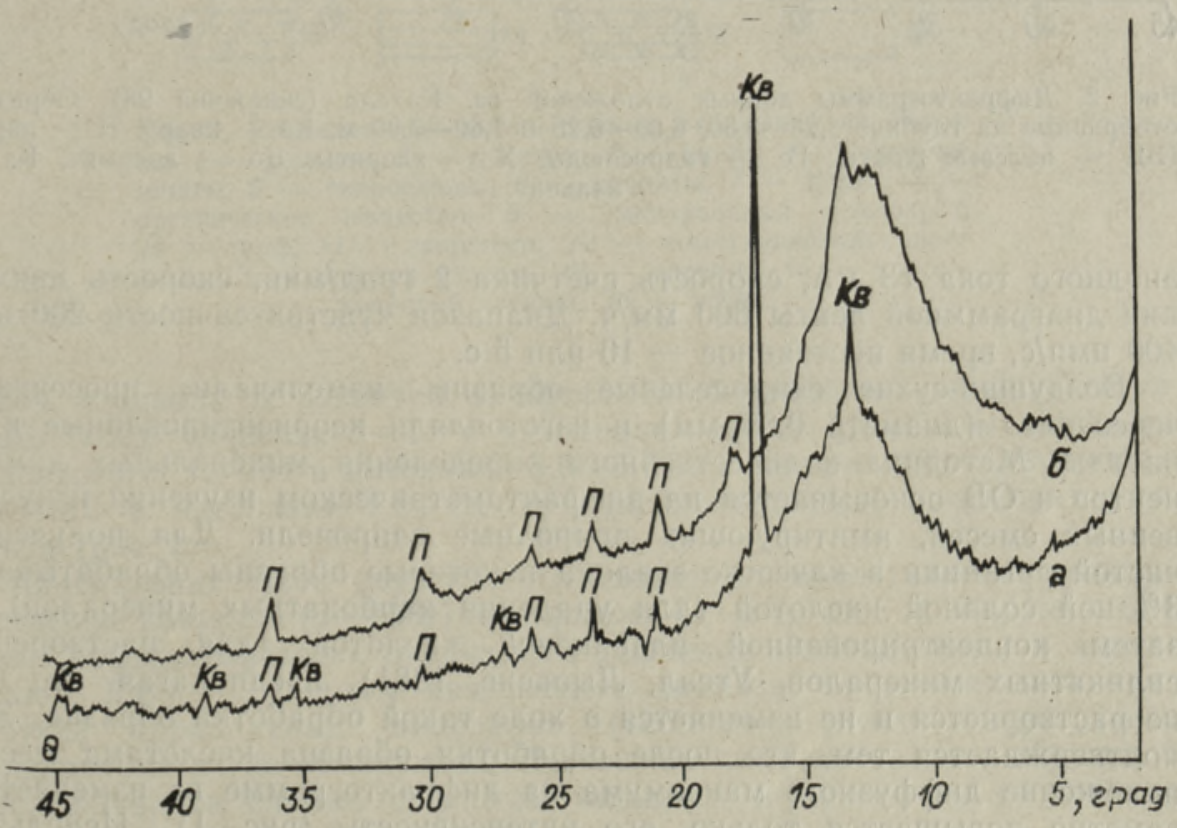

Рис. 1. Дифрактограммы сапропеля оз. Кахала (глубина образца 3,0-3,25 м); $a$ - природный образец, б - после обработки плавиковой кислотой. Кв - кварц, П - пирит. 


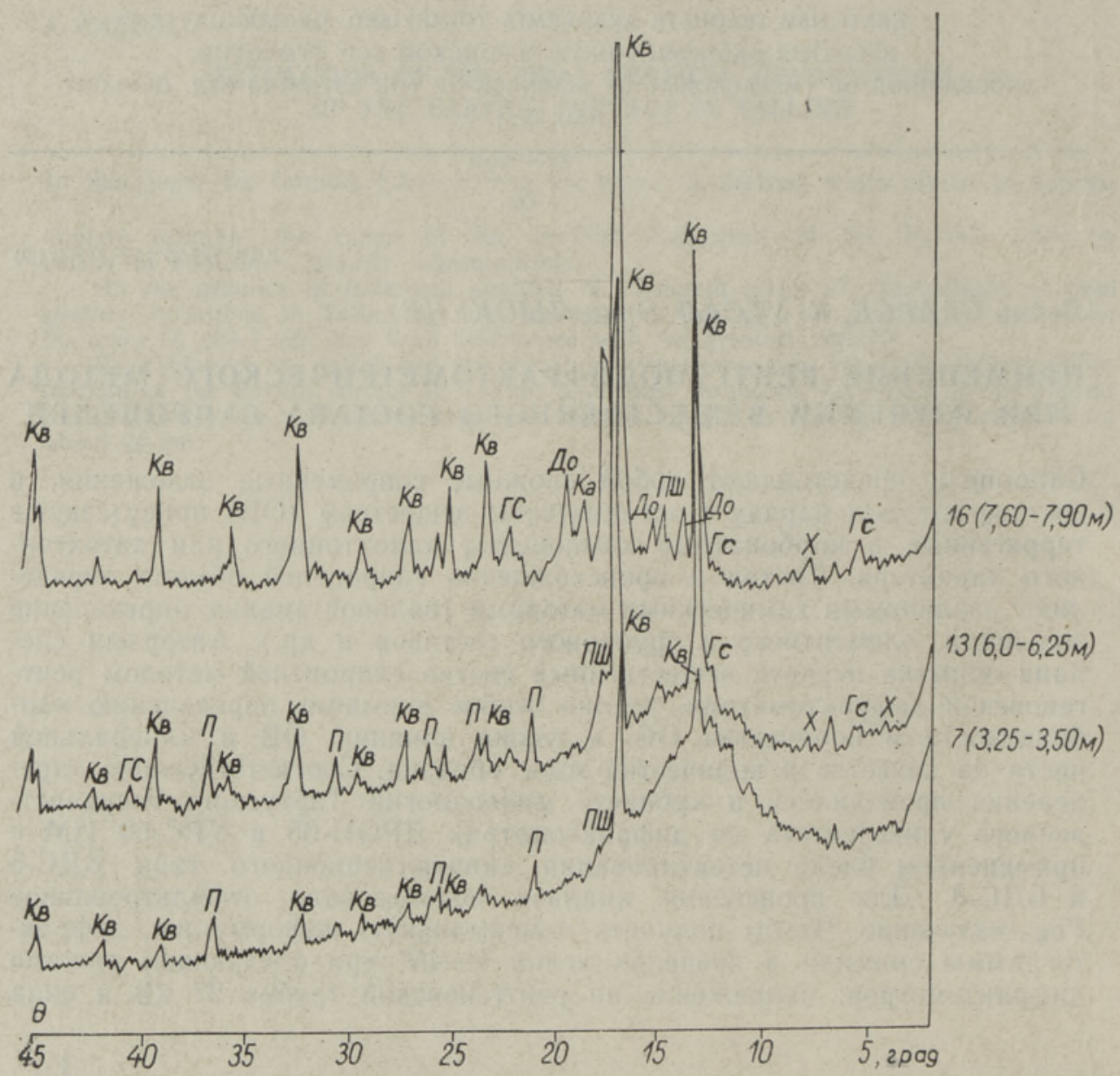

Рис. 2. Дифрактограммы донных отложений оз. Кахала (скважина 96). Образцы, отобранные на глубине $3,25-3,50,6,00-6,25$ и $7,60-7,90$ м. Кв - кварц, П - пирит, ПШ - полевые шпаты, Гс - гидрослюды, X - хлориты, До - доломит, Ка кальцит.

анодного тока 13 мА, скорость счетчика 2 град/мин, скорость движения диаграммной ленты 600 мм/ч. Диапазон чувствительности 200 или 400 имп/с, время постоянное - 10 или 5 с.

Воздушно-сухие сапропелевые образцы измельчали, просеивали через сито (диаметр 0,05 мм) и изготовляли неориентированные препараты. Методика количественного определения минеральных компонентов и ОВ основывается на дифрактометрическом изучении искусственных смесей, имитирующих природные сапропели. Для получения чистой ортаники в качестве эталона некоторые образцы обрабатывали $3 \%$-ной соляной кислотой (для удаления карбонатных минералов), а затем концентрированной плавиковой кислотой (для растворения силикатных минералов, Утсал, Лыокене, 1981), предполагая, что ОВ не растворяется и не изменяется в ходе такой обработки образца. Это подтверждается тем, что после обработки образца кислотами местоположение диффузного максимума на дифрактограмме не изменяется, заметно повышается только его интенсивность (рис. 1). Используя данную методику,-авторы определили вещественный состав отложений оз. Кахала, Выртсъярв и Мяэкюла. Подробнее проанализировали донные отложения оз. Қахала (Северная Эстония), данные о геологи- 

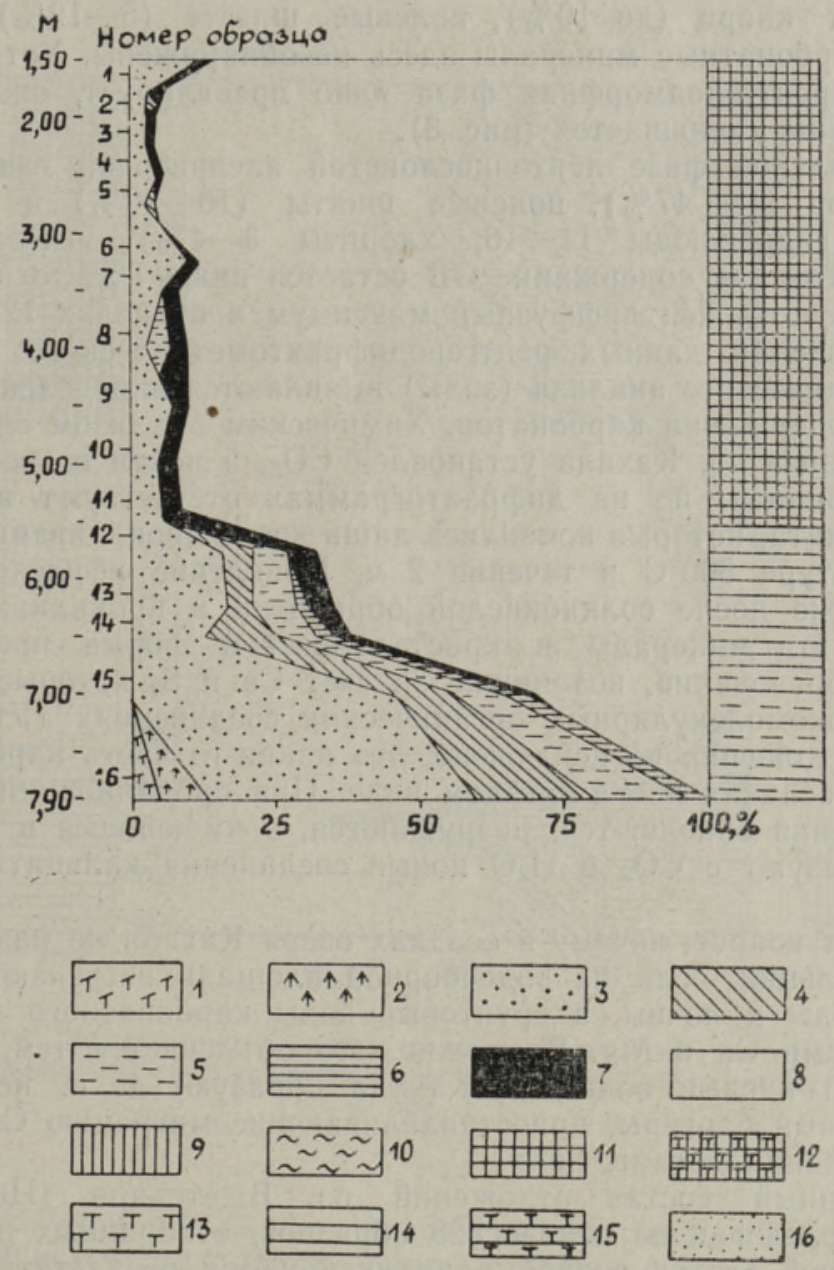

Рнс. 3. Вещественный состав донных отложений 03. Кахала. 1 - кальцит, 2 - доломит, 3 - кварц, 4 - полевые шпаты, 5 - гидрослюды, 6 - хлориты, 7 - пирит, 8 органическое вещество, 9 - минеральный компонент, 10 - торф, 11 - сапропель, 12 - известковистый сапропель, 13 - озерная известь, 14 - алеврит, $15-$ известковистый алеврит, $16-$ песок.

ческом строении и развитии которого опубликованы ранее (Кессел и др., 1982). Образцы $1-11$ в интервале глубин $1,5-5,4$ м взяты со студенистого, $12-14$ в интервале $5,5-6,7$ м с алевритистого сапропеля и $15-16$ в интервале $6,8-7,9$ м с ленточнослоистого алевритового пелита (рис. 2).

Минеральная фаза студенистого сапропеля представлена преимущественно кварцем $(3-10 \%)$ и пиритом $(1-3 \%$, рис. 2,3$)$. На некоторых дифрактотраммах отмечаются рефлексы полевых шпатов и гидрослюд. Хотя, по данным химического анализа, предполагалось присутствие карбонатных минералов (таблица), рентгеноструктурные исследования их не обнаружили. Только на дифрактограмме образца 4 прослеживались слабые рефлексы кальцита и арагонита (последние за счет фрапментов субфоссилий).

В алевритистых сапропелях (образцы 12-14, рис. 2) идентифицированы глинистые минералы - гидрослюды и хлориты. Постоянно 
присутствуют кварц (до $10 \%$ ), полевые шпаты $(5-12 \%)$ и пирит $(3-5 \%)$. Қарбонатные минералы здесь не обнаружены. Хотя и в этих отложениях рентгеноаморфная фаза явно превалирует, она с увеличением глубины уменьшается (рис. 3).

В минеральной фазе ленточнослоистой алевритовой глины преобладают кварц $(46-47 \%)$, полевые шпаты $(10-20 \%)$ и глинистые минералы (гидрослюды $11-16$, хлориты 3-4\%), исчезает пирит (рис. 2,3 ). Так как содержание ОВ остается ниже $1 \%$, то на дифрактограммах не отражен диффузный максимум в пределах $12-13 \theta$.

При сравнении данных рентгенодифрактометрического анализа с данными химическото анализа (золы) выявляются определенные несовпадения в содержании карбонатов. Химическим анализом во всех изученных образцах оз. Кахала установлен $\mathrm{CO}_{2}$, и почти во всех $-\mathrm{CaO}$ и $\mathrm{MgO}$ (таблица), но на дифрактотраммах отсутствуют пики кальцита и доломита, которые появились лишь после прокаливания образца при температуре $500^{\circ} \mathrm{C}$ в течение 2 ч. Появление рефлексов $\mathrm{CaCO}_{3}$ и $\mathrm{CaSO}_{4}$ даже после солянокислой обработки и прокаливания показывает, что эти минералы в кристаллической форме представляют собой новообразования, возникшие за счет $\mathrm{Ca}$ и S, которые присутствуют в высокомолекулярных органических соединениях (Утсал, Лыокене, 1981). Конечно, не исключено, что какая-то часть карбоната может быть в осадках и в аморфном виде. При прокаливании органические соединения окисляются, разрушаются, а имеющиеся в их составе $\mathrm{Ca}$ и $\mathrm{S}$ образуют с $\mathrm{CO}_{2}$ и $\mathrm{H}_{2} \mathrm{O}$ новые соединения кальцита и ангидрита.

Возникает вопрос, почему в осадках озера Кахала не накапливался карбонат кальция, если на водосборной площади встречаются карбонатные породы и почвы, а трунтовые воды карбонатного плато обогащены ионами $\mathrm{Ca}$ и $\mathrm{Mg}$. Возможно, это объясняется тем, что нейтральные или кислые воды оз. Қахала образуют т. н. нейтральный или кальциевый барьеры, приостанавливающие миграцию Са и накопление его в донных отложениях.

Вещественный состав отложений оз. Выртсъярв (Центральная Эстония) исследован на основе 328 образцов, отобранных из 25 скважин. В данной статье подробно анализируются результаты изучения

Содержание карбонатов и ОВ в донных отложениях 03. Кахала (скважина 96), \%

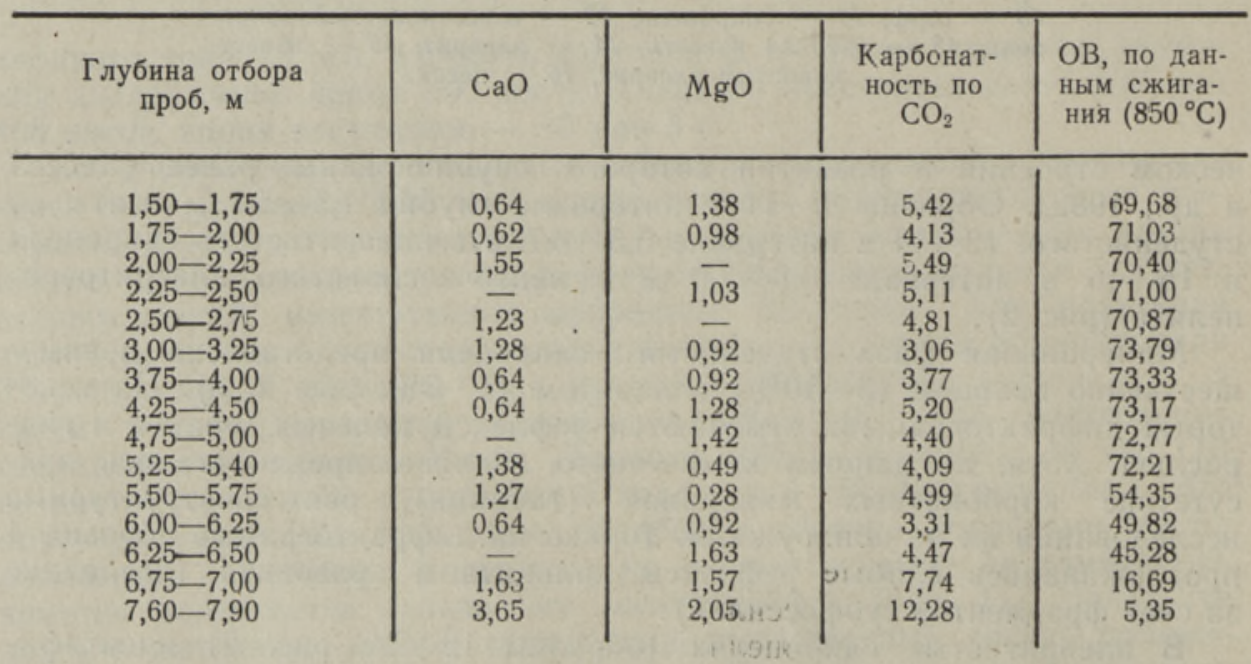

Пр и меч ан ие. Анализы провела Ы. Роос. 


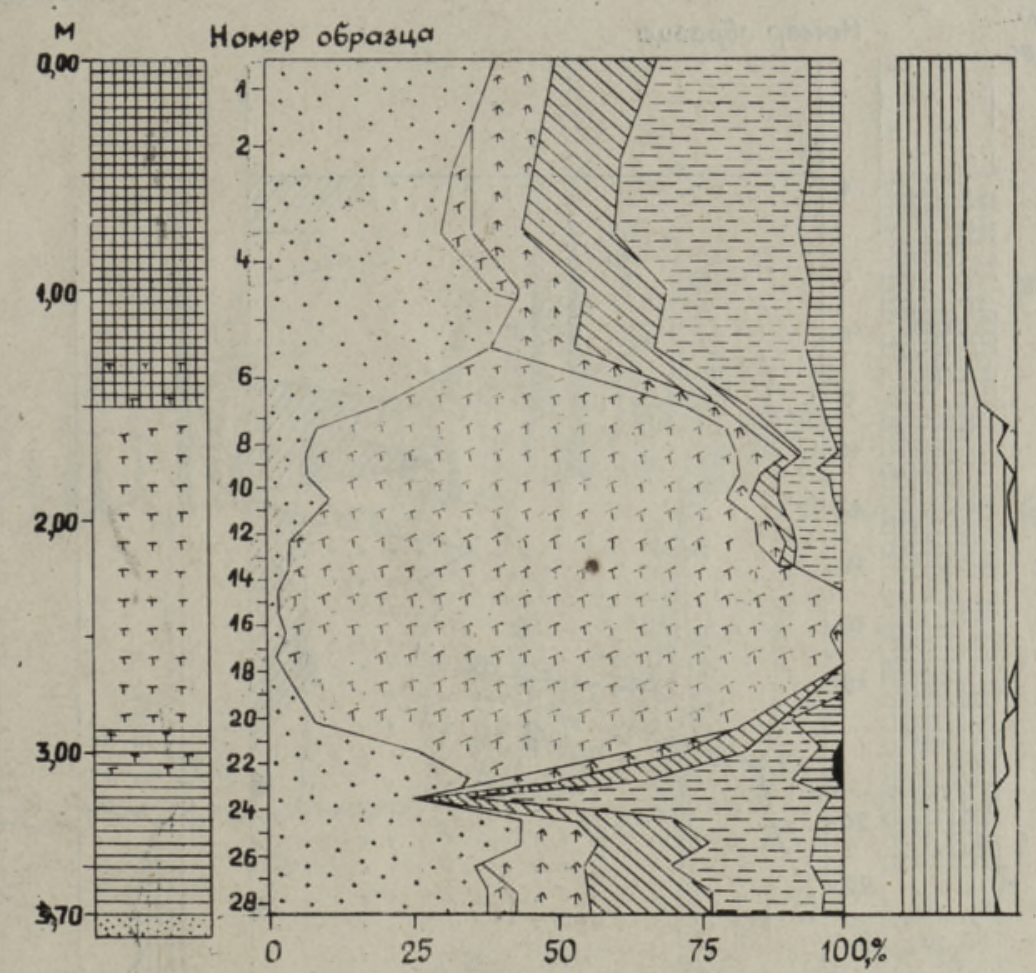

Рис. 4. Вещественный состав донных отложений оз. Выртсъярв (скважина 15, средняя часть озера). Условные обозначения см. на рис. 3 .

донных отложений скважины № 15 (средняя часть озера). Здесь под песчано-глинистым сапропелем залегают относительно чистая озерная известь и алеврит (рис. 4). В сапропеле (образцы $1-5$, в интервале глубин $0-1,25$ м от поверхности слоя) содержится примерно $38-41 \%$ ОВ и $59-62 \%$ минеральных компонентов. Доминируют кварц $(19-25 \%)$, гидрослюды $(9-20 \%)$, хлориты $(3-5 \%)$, полевые шпаты $(4-10 \%)$, доломит $(4-8 \%)$. Кальцит отсутствует или встречается в единичных образцах в незначительном количестве (до $3 \%$ ). В озерной извести (образцы 7-20, глубина 1,50-2,90 м) обнаружены кальцит $(60-98 \%)$ и кварц $(2-10 \%)$, местами гидрослюды (до $9 \%)$, полевые шпаты (до $3 \%$ ) и доломит (до $8 \%$ ). Содержание ОВ ничтожно, только на контактах с вмещающими отложениями оно увеличивается до $16 \%$. Алеврит (образцы $22-29$, глубина $3,0-3,7$ м) содержит $78-93 \%$ минеральното компонента и $7-22 \%$ ОВ. Из минералов установлены кварц $(12-37 \%)$, полевые шпаты $(7-19 \%)$, гидрослюды $(16-59 \%)$, хлориты $(1-5 \%)$, доломит $(5-14 \%)$. Редко встречаются кальцит (до $5 \%$ ) и пирит (1\%).

В долинном 03. Мяэкюла (Сакалаская возвышенность) накапливались сапропель, известковистый сапропель и сапропелевая озерная известь общей мощностью 8 м (рис. 5). В сапропеле (образцы $1-12$, глубина $1,1-4,0$ м) количество ОВ весьма значительное $(86-91 \%)$. Терригенная примесь представлена лишь кварцем $(7-12 \%)$ и на отдельных уровнях кальцитом. В известковистом сапропеле (образцы $13-21$, тлубина $4,0-7,0$ м) ОВ меньше $(56-84 \%)$. С увеличением глубины содержаңие кальцита постепенно доходит до $15-42 \%$, что можно изобразить: непрерывной кривой. Количество кварца незначи- 


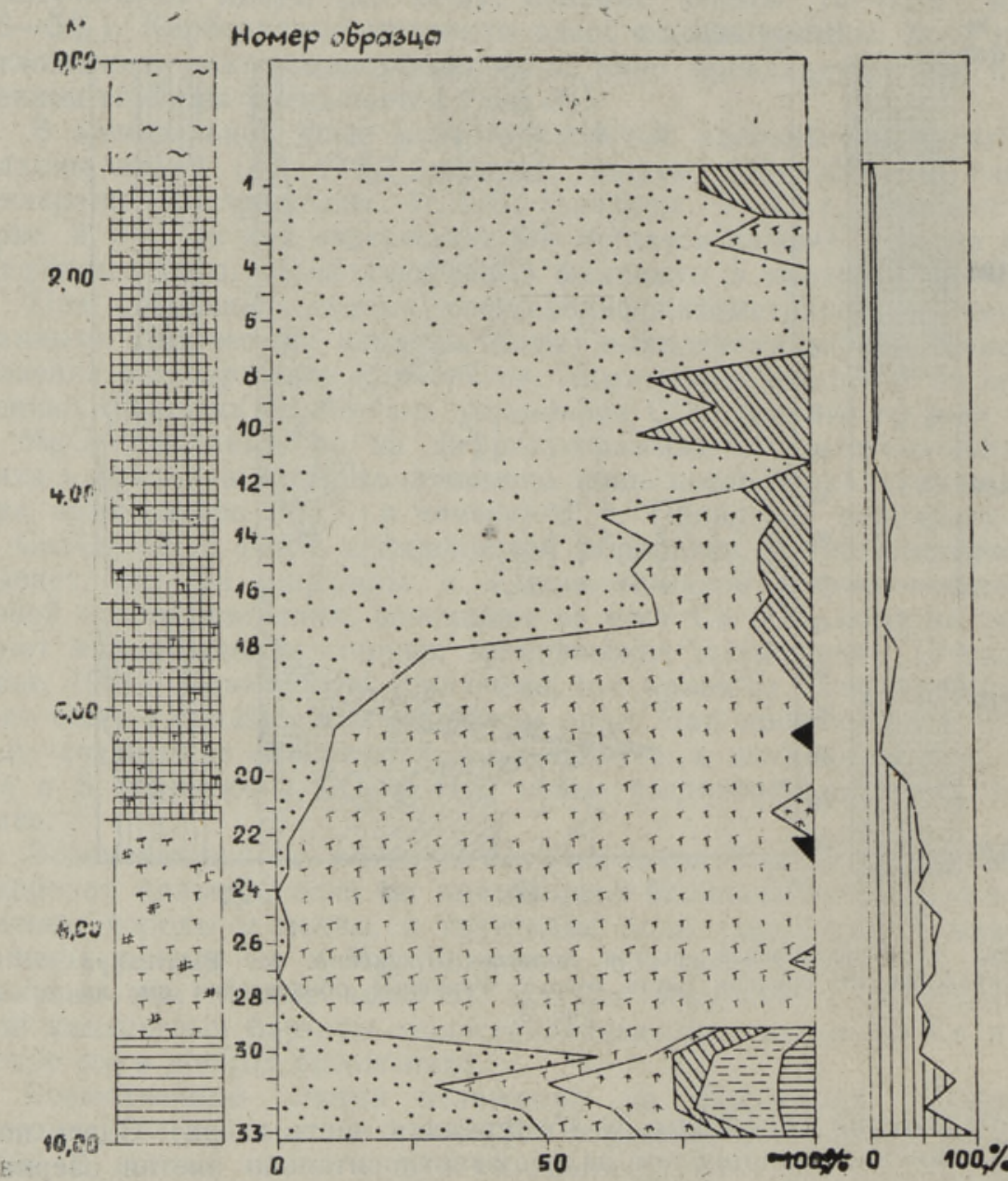

Рис. 5. Вещественный состав донных отложений оз. Мяэкюла. Условные обозначения см. на рнс. 3 .

тельно $(1-7 \%)$. В единичных образцах обнаружен пирит (до $1 \%$ ). В сапропелевой озерной извести с прослойками известковистого сапропеля явно превалируют кальцит $(42-72 \%)$ и ОВ $(27-56 \%)$. Терригенного материала также немного - кварца $1-6 \%$, гидрослюд до $3 \%$. Алеврит (послойно обогащен ОВ, образцы 30-33, глубина $9,0-10,0$ м) содержит $60-65 \%$ минеральной фазы и $20-40 \%$ OB. Минеральные компоненты представлены кварцем $(30-47 \%)$, гидрослюдами $(6-12 \%)$, хлоритами $(4-6 \%)$, полевыми шпатами $(2-5 \%)$, доломитом $(2-19 \%)$ и кальцитом. Сапропели оз. Мяэкюла представляют интерес и в том отношении, что в их составе обнаружены аморфные и коллоидные окислы железа, которые после прокаливания образца в течение 3 ч при температуре $1000^{\circ}$ выкристаллизовывались в гематит (рис. 6) (Утсал и др., 1979). Содержание аморфных фаз железа повышает фон дифрактограмм и значительно затрудняет определение количества ОВ (рис. $6 a, \sigma)$.

Для определения количества ОВ в сапропелях до последнего времени применялись химические методы (окисление осадка перекисью водорода, бихроматом калия в сильнокислой среде; мокрое сжигание по Кнопу прокаливание на газоанализаторе ГОУ; вычисление по эле- 


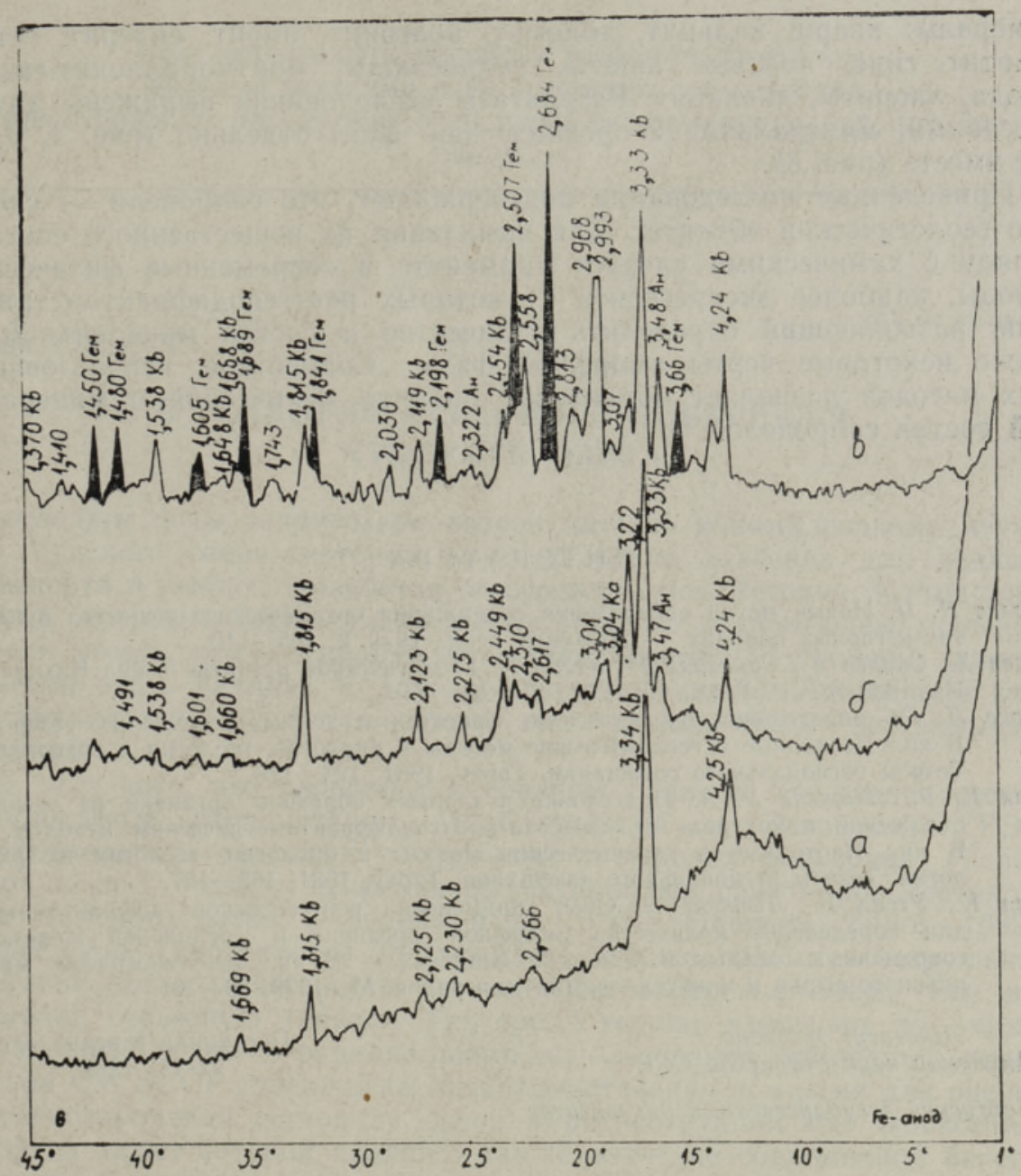

Рис. 6. Дифрактограммы сапропеля оз. Мяэкюла (образец 6, глубина 2,4 м); $a-$ природный образец, б- после прокаливания в течение 5 ч при $550^{\circ} \mathrm{C}$, в - после прокаливания в течение 3 ч при $1000^{\circ} \mathrm{C}$.

ментному составу и др.). Достоинства и недостатки названных методов проанализированы ранее (Бетелев, 1979; Саарсе, 1981). Сравнивая полученные методом сжигания данные содержания ОВ с данными, полученными на основе высоты диффузного максимума дифрактограмм, выяснили, что количество ОВ по рентгенодифрактометрическому анализу всегда примерно на $10 \%$ превышает его количество при сжигании. Причина кроется в том, что в рентгеноаморфной фазе суммируются как неорганическая рентгеноаморфная (аморфный кремнезем, аморфные соединения железа и др.), так и органическая рентгеноаморфная фазы (только органическая часть сапропеля). Наша будущая задача и состоит в том, чтобы разработать основы разделения и интерпретации рентгеноаморфной фазы.

Сведения о сапропелях современных озер, полученные в этой работе, дают достаточно исчерпывающее представление о составе минеральной части отложений и о соотношениях минеральной и органической составляющих. Рентгенодифрактометрическим методом в озерных отложениях и в пелотене озер Әстонии установлены следующие 
минералы: кварц, кальцит, доломит, арагонит, пирит, сидерит, гетит, гематит, гипс, полевые шпаты, тидрослюды, монтмориллонит-гидрослюда, хлориты, каолинит. Результаты исследования выражены двумя способами: минеральная и органическая части отдельно (рис. 4,5$)$ и обе вместе (рис. 3).

Приведенные исследования подтверждают, что сапропели - сложные геологизческие объекты. Для выявления их вещественного состава наряду с химическими следует применять и современные физические методы, наиболее экопрессивен из которых рентгенодифрактометрический; позволяющий определить количество и состав минеральной, 'а также некоторые черты аморфной фазы. Совместное использование этих методов позволяет объективно оценить химический и минеральный состав сапропелей.

\section{Л ИТ Е Р А Т Р А}

Бетелев Н. П. Новый метод определения содержания органического вещества в грунтах и горных породах. - Инженер. геол., 1979, 2, 105-110.

Кессел Х., Саарсе Л., Синисалу Р., Утсал К. Геологическое развитие озера Кахала. Изв. АН ЭССР. Геол., 1982, 31, 21-28.

Caарсе $Л$. Об определении органического вещества в донных отложениях озер. В кн.: Изотопные и геохимические методы в биологии, геологии и археологии. Тезисы регионального совещания. Тарту, $1981,124-128$.

Утсал K. Р., Лыокене Э. А. Подготовка эталонных образцов органики из озерных отложений и контроль ее качества рентгендифрактометрическим методом. В кн.: Изотопные и геохимические методы в биологии, геологии и археологии. Тезисы регионального совещания. Тарту, 1981, 165-167.

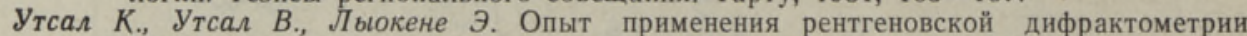
для определения количества аморфной органики и соединений железа в современных озерных и болотных осадках. - В кн.: Рентгенография минерального сырья и крнсталлохимня минералов. М., $1979,56-76$.
Ннститут геологии
Академии наук Эстонской ССР
Поступила в редакцию 22/XII 1982

Тартуский государственный университет

Leili SAARSE, K. UTSAL, Erna LOOKENE

\section{RONTGENDIFRAKTOMEETRIA KASUTAMINE SAPROPEELI KOOSTISE UURIMISEKS}

Artiklis on esitatud näide sapropeelide koostise röntgendifraktomeetrilisest uurimisest ning toodud andmeid Kahala, Mäeküla ja Vōrtsjärve pōhjasetete koostise kohta.

\section{Leili SAARSE, K. UTSAL, Erna LOOKENE}

\section{APPLICATION OF THE X-RAY METHOD FOR THE STUDY OF THE COMPOSITION OF GYTTJA}

The authors propose the $\mathrm{X}$-ray as a rapid method for the investigation of the mineralogical composition of gyttja (sapropel). Unoriented samples were made from the powder of gyttja (less than $0.05 \mathrm{~mm}$ in diameter). For the interpretation of minerals the heating treatment, $\mathrm{HCl}$ and $\mathrm{HF}$ was used. On the basis of the height and the area of the peak of the diffusional maximum (about $12-14 \Theta$ ) the amount of organic matter was calculated. The simultaneous use of the chemical and X-ray data contributes to a trustworthy interpretation of the mineralogical composition of gyttja. Up to now the following minerals have been identified from the bottom deposits of Estonian lakes: quartz, calcite, dolomite, aragonite, pyrite, siderite, goethite, hematite, gypsum, feldspar, hydromicas, montmorillonite-hydromica, chlorites and kaolinite, 